ORIGINAL ARTICLE

\title{
THE RATE OF SUCCESS IN UTEROVAGINAL PACKING IN ATONIC UTERUS IN A TERTIARY CARE HOSPITAL IN LOW RESOURCE SETTING
}

\author{
Samina Aliya Sabir, Shahida Sultan \\ Department of Gynaecology and Obstetrics, Lady Reading Hospital, Peshawar - Pakistan
}

\begin{abstract}
Objective: To find out the success rate of Uterovaginal packing of Atonic Uterus in a tertiary care hospital, in low resource setting.

Methods: This was a cross-sectional study conducted in Gynaecology and Obstetrics department of Lady Reading Hospital from January 2019 to December 2019. Our study included those patients with PPH not responding to medical treatment in vaginal delivery. Patients in shock with PPH and PPH after Caesarian section were excluded from the study. The study was approved by the ethical committee of hospital.
\end{abstract}

Results: In our study 250 patients with Atonic Uterus were subjected to uterovaginal packing after medical treatment failed in these patients. The success rate after 12 hours was $86.4 \%$. In rest of the patients, PPH was controlled by second line surgical intervention in 34 cases (13.6\%), B Lynch in 18 (7.2\%) cases, subtotal hysterectomies in $13(5.2 \%)$ cases and internal lliac ligation in 3 cases $(1.2 \%)$

Conclusion: Uterovaginal packing is an effective, easy, quick and lifesaving method in the control of PPH in low resource settings.

Key Words: Primary postpartum hemorrhage, Internal lliac Ligation, Retained products of conception(RPOCs)

This article may be cited as: Sabir SA, Sultan S. The Rate of Success in Uterovaginal packing in Atonic Uterus in a tertiary care hospital in low resource setting. J Med Sci 2021 July;29(3):96-98

\section{INTRODUCTION}

Worldwide, 5 million maternal deaths occur annually, out of which, 150,000 are due to $\mathrm{PPH} .{ }^{1}$ In developing countries, the risk of maternal deaths from PPH is 1 in 1000 deliveries. ${ }^{2,3}$ Moreover, PPH may result in serious morbidities like coagulopathy and renal shutdown. Uterine Atony is the leading cause of PPH in more than $90 \%$ of cases. ${ }^{4}$ In these cases, uterotonics are given and if not effective, then before proceeding to operative procedures like $B$ lynch, internal iliac ligation and hysterectomies, an alternative and more conservative procedure of Uterovaginal packing can be applied. ${ }^{5,6}$ It compresses the uterine sinuses by pressure effect just like Balloon Tamponade and hence controls bleeding by quick and cheap way in a low resource setting. In most cases bleeding stops and patient is saved from invasive procedures. In other cases, patient is stabilized while preparing for surgery and sometimes surgery is not

\section{Correspondence}

Dr. Samina Aliya Sabir

Department of Gynaecology and Obstetrics, Lady Read-

ing Hospital, Peshawar - Pakistan

Email: sam_sabir@hotmail.com

Cell: +92-334-9651331

Date received: $\quad 05-11-2020$

Date revised: $08-05-2021$

Date accepted: $12-07-2021$ needed as the bleeding gets stopped with this conservative procedure. ${ }^{7,8}$

We conducted this study to see the success of this procedure in low resource settings having a high rate of $\mathrm{PPH}$. No studies have been conducted on this procedure in the recent years despite the fact that it is being frequently used to control PPH in tertiary care hospitals.

\section{MATERIALS AND METHODS}

This was a cross-sectional study conducted in Lady Reading Hospital Peshawar from January 2019 to December 2019. Patients with PPH with Atonic uterus were included in the study. Those in shock due to $\mathrm{PPH}, \mathrm{PPH}$ after $\mathrm{C}$ section, secondary $\mathrm{PPH}, \mathrm{RPOC}$ and genital tract trauma were excluded from the study. The sample size of 250 was calculated by WHO sample size calculator by taking the prevalence of $\mathrm{PPH}$ in pregnancy as $7 \%$, confidence interval $95 \%$ and margin of error as $5 \%$. The study was approved by ethical committee of the hospital. After informed consent, patients were included the study, and a detailed history and clinical examination was done.

Under good light, Sims speculum was passed with cervix held with Volsellum. A 6-meter sterilized gauze was passed layer by layer starting from fundus occupying the whole uterine cavity till the cervix. Further, this packing was 
THr Rate Of Success In Uterovaginal Packing In Atonic Uterus In A Tertiary Care Hospital In Low Resource Setting

extended into the vagina to add pressure and good compression to the uterus. Prophylactic single dose antibiotic was given, the pack was kept for 12 hours and Syntocinon infusion was continued for 6 hours. Patients were kept in High Dependency Unit with strict vital record. Patient were declared stable after 12 hours without any untoward events. Data of these patients was analyzed using the SPSS version 23.

\section{RESULTS}

A total of 413 patients of PPH presented to the unit in this study period, out of which 250 patients with Atonic uterus underwent uterovaginal packing. The maternal age was $34.6 \pm 4.68$, Gestational age was $36.2 \pm 1.65$ and Parity was $6.08 \pm 1.64$ (as shown in Table 1).

The success rate of uterovaginal packing after 12 hours was $86.4 \%$ as given in Table 2 and $13.6 \%$ needed second line surgical intervention as can be seen in Table 3. Subtotal hysterectomy was performed in 13 patients $(5.2 \%)$, B Lynch was done in 18 cases $(7.2 \%)$, and Internal iliac ligation was done in 3 patients (1.2\%). Mortality of these patients in the study period was found to be zero.

Table 1: No of patients coming with PPH $(n=413)$

\begin{tabular}{|c|c|c|}
\hline Causes of PPH & $\begin{array}{c}\text { Number of } \\
\text { patients }\end{array}$ & Frequencies \\
\hline Atonic Uterus & 250 & $\% 60.53$ \\
\hline $\begin{array}{c}\text { Genital Tract } \\
\text { Trauma }\end{array}$ & 43 & $\% 10.72$ \\
\hline RPOCs & 61 & $\% 14.76$ \\
\hline Retained Placenta & 47 & $\% 11.38$ \\
\hline Coagulopathy & 12 & $\% 2.90$ \\
\hline
\end{tabular}

Table 2: Demographic features of patients with PPH

\begin{tabular}{|c|c|}
\hline Variables & Mean \\
\hline Maternal age & $4.68 \pm 34.6$ \\
\hline Gestational age & $1.65 \pm 36.2$ \\
\hline Parity & $1.64 \pm 6.08$ \\
\hline
\end{tabular}

Table 3: Success Rate of Uterovaginal Packing ( $n=250$ Patients)

\begin{tabular}{|c|c|c|}
\hline Procedure & No of patients & Frequency \\
\hline Uterovaginal packing & 226 & $\% 86.4$ \\
\hline $\begin{array}{c}\text { Second line surgical } \\
\text { intervention }\end{array}$ & 34 & $\% 13.6$ \\
\hline
\end{tabular}

\section{DISCUSSION}

$\mathrm{PPH}$ is a major cause of maternal morbidity and mortality. Uterovaginal packing was used to control $\mathrm{PPH}$ in 1960s, but due to the risk of infection, its use declined. But in 1990s, its use again started to gain popularity. ${ }^{9}$ This modality is most useful in controlling bleeding due to Atonic uterus not responding to medical treatment and placenta previa and accreta. ${ }^{6}$ Uterine packing has been recommend- ed by Begga et al. to control bleeding in cases of uterine atony not responding to medical treatment ${ }^{9}$.

In the present study the success rate of controlling the bleeding was $86.4 \%$ which was comparable to studies done by Bagga R, $84.7 \%$ by Pradhan B et al, $86 \%$ by Haq et al, , $86 \%$ by Bhatti K et al, $91.8 \%$ by Singh P et al. ${ }^{9,10.12,13,14}$ In the study done by Ali et al. on uterovaginal packing in $46(86 \%)$ patients with $\mathrm{PPH}, 14$ patients failed to achieve haemostasis with $6(14 \%)$ patients having caesarean hysterectomy, internal iliac ligation in $3(7 \%)$ patients, 4 patients had $b$ Lynch, 1 (2\%) died and 13 patients had multiorgan failure. These results were comparable to our results in success and second line invasive procedures used were the same.${ }^{15}$ Uterine gauze packing is also effective in cases of bleeding from placental bed in cases of placenta accreta by Shao et al. ${ }^{16}$

In studies done by Haq et al and Nwagha et al. reported uterovaginal packing as 12-24 hours according to the cases. In our study, we kept the pack for 12 hours while monitoring the vitals and increase in fundal height. ${ }^{12,17}$

Our study results were comparable to a 4 years' observational study in low resource setting in which Foley's catheter had a 53\% efficacy in controlling PPH and the uterovaginal packing had a much higher efficacy of $93 \%$. Second line surgical intervention is the only option in patients with $\mathrm{PPH}$ to control the bleeding in which conservative management fails. In our study, 34 patients (13.6\%) underwent surgical intervention which were comparable to surgical intervention for PPH done in other study done by Iram et al. ${ }^{18}$

In developing countries, $70 \%$ of patients are delivered without skilled birth attendants and there are no facilities and expertise available for advanced procedures like pelvic devasculirization and balloon tamponade. In such circumstances, uterovaginal packing is a good substitute for tamponade and can be done by less trained birth attendant to control bleeding and in the meanwhile, referring patient to a tertiary care hospital, because time is of prime importance in cases of PPH to save the life of a patient.

Limitations of this study include, small sample size and single center experience. Further large scale studies are required to compare Uterovaginal packing with balloon tamponade.

\section{CONCLUSION}

Uterovaginal packing is a quick, economical and effective procedure in controlling bleeding in $\mathrm{PPH}$ in hemodynamically stable patients and can be done by a less expert medical personnel in a low resource setting.

\section{REFERENCES}

1. World Health Organization. Trends in maternal mortality 2000 to 2017: estimates by WHO, UNICEF, UNFPA, World Bank Group and the United Nations Population 
Division.

2. Group CC. Countdown to 2015 for maternal, newborn, and child survival: the 2008 report on tracking coverage of interventions. The Lancet. 2008 Apr 12;371(9620):124758.

3. National Institute for Clinical Excellence. Scottish Executive Health Department and Department of Health, Social Services and Public Safety: Northern Ireland (2001) Confidential Enquiries into Maternal Deaths in the United Kingdom 1997-99. TSO, London.

4. Ghezzi F, Cromi A, Uccella S, Raio L, Bolis P, Surbek D. The Hayman technique: a simple method to treat postpartum haemorrhage. BJOG: An International Journal of Obstetrics \& Gynaecology. 2007 Mar;114(3):362-5.

5. Javed L, Munir SI, Eusaph AZ. Effectiveness of Utero-Vaginal Packing in Management of Postpartum Hemorrhage. Annals of King Edward Medical University. 2017 Mar 11;23(1).

6. Al-Harbi NA, Al-Abra ES, Alabbad NS. Utero-vaginal packing. Saudi Med J. 2009;30(2):243-6.

7. Sarkar M, Mandai J, Roy D. Uterovaginal packing with rolled gauze in post-partum haemorrhage, a retrospective study in Malda medical college, West Bengal. Journal of Evolution of Medical and Dental Sciences. 2019 Jul 8;8(27):2162-6.

8. Mousa HA, Blum J, Abou El Senoun G, Shakur H, Alfirevic $Z$. Treatment for primary postpartum haemorrhage. Cochrane database of systematic reviews. 2014(2).

9. Bagga R, Jain V, Chopra S, Kalra J, Gopalan S. Uterovaginal Packing With Rolled Gauze in Postpartum Hemorrhage: Case Report. Medscape General Medicine. 2004;6(1):50.

10. Pradhan B, Laxmi RC, Sharma P, Singh A. Uterovaginal Packing as Treatment in Primary Postpartum Hemorrhage in Patan Hospital. Nepal Journal of Obstetrics and Gynaecology. 2016 Dec 26;11(1):44-6.

11. Rezk M, Saleh S, Shaheen A, Fakhry T. Uterine packing versus Foley's catheter for the treatment of postpartum hemorrhage secondary to bleeding tendency in low-resource setting: A four-year observational study. The Journal of Maternal-Fetal \& Neonatal Medicine. 2017 Nov $17 ; 30(22): 2747-51$

12. Haq G, Tayyab S. Control of postpartum and post abortal haemorrhage with uterine packing. Journal-Pakistan Medical Association. 2005 Sep 1;55(9):369.
13. Bhatti K, Lashari AA, Mahar T, Hafeez R. Intrauterine packing in postpartum hemorrhage still a lifesaving procedure in resource-poor settings. Rawal Medical Journal. 2014 Oct;39(4):432-4.

14. Singh P, Naniwal A. Role of Intrauterine Packing in Primary Post-Partum Haemorrhage. Medical Science. 2016 Jul;5(7)

15. Ali TA, Ghazi AS, Siddiq NM. Uterovaginal packing in massive postpartum hemorrhage-a reappraisal. Pak J Surg. 2008;24(1):57-9.

16. Pradhan $M$. Intrauterine gauze packing in primary post-partum hemorrhage following caesarean section: a clinical study. Nepal Journal of Obstetrics and Gynaecology. 2012;7(1):33-6.Pradhan M. Intrauterine gauze packing in primary post-partum hemorrhage following caesarean section: a clinical study. Nepal Journal of Obstetrics and Gynaecology. 2012;7(1):33-6.

17. Akintan AL, Oluwasola TA, Aderoba AK, Owa OO, Oyeneyin OL. Intraoperative uterine packing with abdominal mops as adjunct management of postpartum haemorrhage in a low resource settin. African Journal of Medicine and Medical Sciences. 2021 May 18;50(1):4956.

18. Iram M. Role of uterine packing in control of PPH. PJMHS. 2011;5(3):442-4.

CONFLICT OF INTEREST: Authors declare no conflict of interest

GRANT SUPPORT AND FINANCIAL DISCLOSURE: NIL

\section{AUTHOR'S CONTRIBUTION}

Following authors have made substantial contributions to the manuscript as under

Sabir SA: Idea, Proposal Writting, Data collection, Writting.

Sultan S: Data collection, Writting

Authors agree to be accountable for all aspects of the work in ensuring that questions related to the accuracy or integrity of any part of the work are appropriately investigated and resolved. 